\title{
Rediscovering the power of physical relief models: Mayson's Ordnance Model of the Lake District
}

Gary Priestnall, School of Geography, The University of Nottingham.

\section{Abstract}

Mayson's Ordnance model of the Lake District, commissioned by Henry and Thomas Mayson from sculptor Raffaelle Monti in 1875 was based upon early maps from Ordnance Survey, the government mapping agency for Great Britain. It was displayed in the town of Keswick, now in Cumbria, England until around 1980 when it is believed to have been destroyed. A large number of original negative moulds from the model were recovered, together with other historical objects, allowing the unique characteristics of the model to be explored for the first time. The study reveals the model to have been innovative for its time, being a very early example of a relief model constructed from contours. The scientific authority of the model, along with its cartographic detail and size, were used to promote it as a spectacle for early tourists. The article describes a process of digital capture, processing and 3D fabrication to allow parts of the model to be analysed and redisplayed. An exhibition explored public engagement with physical landscape models, included a novel visitorled identification of the remaining moulds. Examples of modern landscape modelling and visualization techniques helped to explore the role physical models could play in the modern visitor experience.

\section{Keywords}

Relief Model, 3D Reconstruction, Digital Terrain Model, Landscape Visualisation, Public Exhibition

\section{Introduction}

In 2013 a large number of negative moulds relating to a landscape model were recovered from storage in Workington, Cumbria. The local museums knew very little about the collection apart from that it may relate to a model known to have been created by the Mayson brothers of Keswick during the Victorian period. This discovery presented an exciting opportunity to explore the local context of display of the original model and to assess its significance in the broader context of the history of relief model making.

Physical landscape models aim to offer viewers a natural perspective through which they can appreciate the spatial interrelationships between places of interest, sometimes orienting people to the local landscape, sometimes giving privileged perspectives on remote areas. Some of the earliest models, termed 'plan-reliefs', were created to document fortified settlements during the seventeenth and eighteenth centuries (Rothrock 1969). The scale was such that the spatial arrangement of individual buildings and defensive structures forming a settlement could be appreciated in the context of very detailed local topography. Moving around such models helped the viewer gain an appreciation of the subtle characteristics of the landscape surrounding the fortifications including relative heights and distances which supported discussions of defensive strategies. Detail and realism in both the terrain and objects on the surface were designed to mimic a landscape as faithfully as possible. An advertisement for the model of the Waterloo battlefield by Captain William Siborne in 1838 suggested that "it is difficult for the spectator to divest himself of the idea that he is beholding a reality instead of a work of art" (Hofschroer 2004, 1). Models were typically large enough to have impact and allow detail to be discerned but on occasions they proved to be less than fit for purpose as reported in Granado-Castro and Martín-Pastor (2016), where a physical model of Cadiz in 1779 proved too large to be used effectively for its intended purpose as a tool for military planning.

From the late eighteenth century a growing interest in the Alps from geographers, geologists and mountaineers prompted the creation of relief models aimed at non-military audiences. Coinciding with the first recorded ascent of Mont Blanc in France, the highest peak in Europe, in 1786 Charles François Exchaquet set about creating a model of the surrounding peaks based upon his own observations and measurements (Touret, 1989). Around this time the Swiss Alps were the focus of several modelling ventures that covered 
much larger areas. One such endeavour was led by Johann Henry Weiss and Joachim Eugen Müller which resulted in Müller creating a relief model measuring $1.5 \mathrm{~m}$ by $4.5 \mathrm{~m}$ at a scale of $1: 60,000$ of the Swiss Alps and surrounding regions in 1797 . Such was the accuracy of the model, based upon a triangulation technique to record the positions of key features, that it was used as the basis for producing a national topographic map of Switzerland (Imhof, 1981).

One model that proved hugely significant in paving the way for later model makers like Müller was that of the area around Lake Lucerne in Central Switzerland completed in 1786 by Lieutenant General Franz Ludwig Pfyffer. The model was a result of over twenty years of surveying, pioneering the use of triangulation and barometric height measurement over large mountainous areas. The model measured $6.7 \mathrm{~m}$ by $3.9 \mathrm{~m}$ and can still be viewed today at the Glacier Garden Museum in Lucerne (Figure 1, left). The model was clearly powerful in giving visitors an overview of the landscape around them and English poet William Wordsworth documented his encounter with it in his guidebook to the English Lake District first published in 1810.

"The spectator ascends a little platform, and sees mountains, lakes, glaciers, rivers, woods, waterfalls, and valleys, with their cottages, and every other object contained in them, lying at his feet; all things being represented in their appropriate colours. It may be easily conceived that this exhibition affords an exquisite delight to the imagination... but it supplies also a more substantial pleasure; for the sublime and beautiful region, with all its hidden treasures, and their bearings and relations to each other, is thereby comprehended and understood at once."

From 'Guide to the Lakes' (Wordsworth 1810, 21).

Wordsworth's encounter with the Pfyffer model influenced the way he invited the readers of his guidebook to imagine overviews of the Lake District 'as if from a cloud'. By the early nineteenth century the area had become a popular destination for the more privileged visitors who may have taken the Grand Tour of the Alps had Britain not been at war with France. Although great advances in cartographic relief representation were being made, particularly in alpine regions as described by Collier and others (2003), guidebooks to the Lake District tended to include only small maps covering large areas with little detail of the terrain. Mountains were at best indicated by 'hachures', lines of steep slope, one of the best examples being that published by Jonathan Otley in 1818 (Smith, 2007).

The steady increase in tourism during the early nineteenth century saw Keswick in the North of the Lake District emerge as one of the main centres for elite tourists arriving by horse-drawn coach (Marshall and Walton, 1981). Keswick became a base for excursions but the town itself had little in the way of visitor attractions until in 1834 a relief model created by Joseph Flintoft went on public display (Figure 1, right) in the town hall. Flintoft had spent seven years surveying the whole of the Lake District, covering an area 51 miles by 37 miles, producing a model measuring 12 feet 9 inches by 9 feet 3 inches at a scale of 3 inches to the mile.
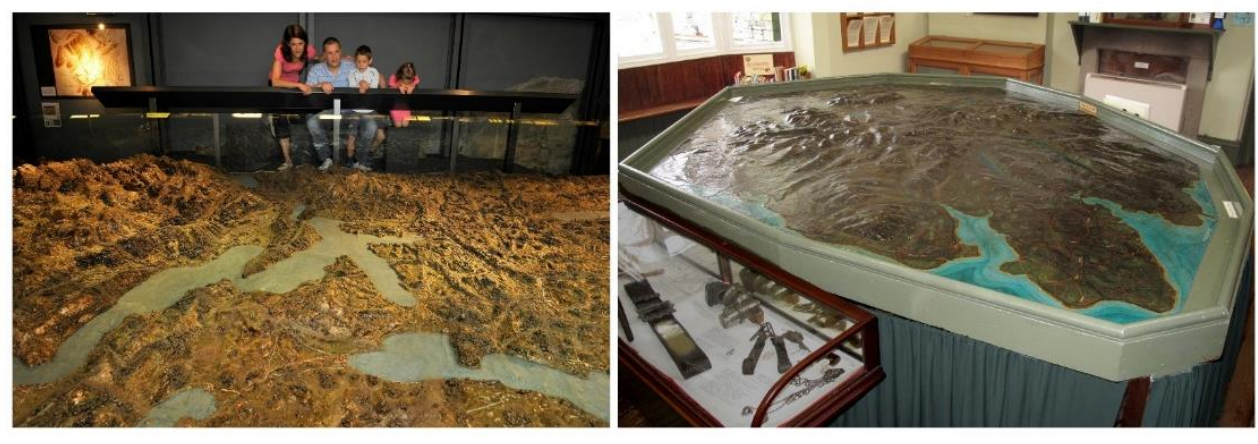
Figure 1 Pfyffer's model of Central Switzerland (left). Photograph used with permission of Madlena Cavelti, Director of the Glacier Garden Museum; Flintoft's Model of the English Lake District (right), photograph by the author.

Flintoft's model became a hugely popular part of the visitor experience in Keswick and was referenced in most guidebooks produced thereafter, for example Jenkinson (1874) includes "At first sight the model looks like a large table of unsightly plaster, but a few minutes' inspection of it will give the tourist a better knowledge of the whole Lake District than he can obtain from a month's study of the maps."

During the second half of the nineteenth century the number of summer visitors is estimated to have increased by factor of five thanks to the coming of the railway which further strengthened Keswick as a hub for horse-drawn excursions (Marshall and Walton, 1981). The new wave of middle class visitors from industrial cities like Manchester increased the demand for maps and guidebooks to orientate them with this unfamiliar landscape (Smith, 1985). Such guides continued to reference Flintoft's model when summarising Keswick's attractions including the popular national railway guide by Bradshaw (1863).

The popularity of the Flintoft model and the increase in visitors to Keswick because of the railway presented an opportunity to Henry Mayson, an entrepreneurial figure trying to establish a photographic studio in the town (Kelly 1991). In 1875 he and his brother Thomas commissioned a bigger and better landscape model to compete with the Flintoft model and attract people into his studio. A few years earlier Ordnance Survey, the government mapping agency, had completed detailed maps of the country which presented Mayson with a source of data to create such a model. Mayson's 'Ordnance' model was displayed in the same building in Keswick until the 1970s, but is thought to have been broken up around 1980.

This paper describes an investigation into the historical significance of Mayson's Ordnance model using moulds recovered from storage and other historical objects that came to light. Digital technologies were used to explore the physical characteristics of the model by capturing the mould surfaces and replicating parts of the model for public display. The study is unusual in that it explores a landscape model indirectly through a body of historical evidence including negative moulds rather than by analysing a model that can still be observed. Direct observation of historical relief models by other researchers has resulted in a number of approaches, some related to exploring the accuracy of the models, whilst others are concerned with their preservation and display.

\section{Approaches to the study of historical relief models}

An example of studying the accuracy of relief models is seen in Niederöst (2005) where the Pfyffer model referred to earlier was captured with the aid of photogrammetric techniques revealing a surprising level of vertical accuracy averaging around $1 \mathrm{~cm}$ in model terms. A relief model by Müller was the subject of research by Pearson and Schaefer (2009) where the model surface was captured using a high-resolution 3D laser scanner. The patterns in horizontal and vertical accuracy of the model as compared to modern survey data from Swisstopo reflected a model making strategy focussed on accurately surveyed 'principal peaks' with less accurate interpolated areas in between.

Some studies have utilised technology to enhance the way models can be viewed by the public. Landscape models representing relatively small geographic areas often capture surface details such as buildings to such a degree that they can represent valuable snap shots in time and can be of great historical as well as cartographic interest. One such example is the model of central Liège completed in 1910 by Gustave RuhlHauzer from maps and detailed plans. A study by Billen and others (2009) described the scanning of the model as being important not only to preserve a 3D representation suitable for visualisation but also to allow a spatial database of features to be created to support archaeological information retrieval and analysis. On occasions physical models can be considered too large for public display, or their size precludes detailed examination of parts of the model, and in such cases scanning has been employed to make the models more 
accessible to the public. Chevrier and others (2010) used laser-scanning to capture a large model of the town of Toul in France built in the 1840s to enable detailed representations of this to be presented on the internet and also via interactive terminals within a museum. Guidi and others (2005) describe the challenge of scanning a model of Rome, measuring $16 \mathrm{~m} \times 17 \mathrm{~m}$, in many blocks, to allow the capture of fine detail, with a view to helping create a virtual model of ancient Rome.

Some historical relief models have had their display enhanced through additional content often using spotlights to identify parts of the model when presenting information on a screen, as with Siborne's model of Waterloo at the National Army Museum in London. A similar but more interactive version is seen in Ma and others (2013) who illuminate parts of a 'plan-relief' of the French city of Nantes created in 1900 to locate virtual reconstructions shown on screens next to the model. Using the same case study a broader framework for representing physical models alongside other museum information is described by Hervy and others (2014).

Physical relief models could be seen as examples of true 3D visualisation, allowing the viewer to appreciate spatial relationships in the landscape through direct human stereo vision. In the digital age there are now many possibilities for exploring 'true 3D' as reviewed in Buchroithner (2012) some of which involve various forms of solid model. The increasing availability of digital terrain surface data and additional options for creating models, such as 3D printing (Rase, 2012) opens up new opportunities to explore the role of solid models. New applications such as tactile maps for the visually impaired (Schwarzbach and others, 2012) benefit from the ability to manipulate digital terrain data to create physical models designed for particular purposes. The traditional static colouring of relief models can be replaced by time series data through projection onto unpainted models, for example in demonstrating the historical development of Dresden (Hahmann and others, 2012). Here again the ability to manipulate digital terrain data allowed recent anthropogenic features on the landscape to be removed.

Many studies have placed great emphasis on physical relief models as objects of historical significance and on the opportunities and challenges for both conserving and displaying them. The same would hold true for this study of the Mayson model, however the material objects under investigation here are significantly different in that only negative moulds were available rather than the original model itself. There was therefore a requirement for a different technical approach that not only captured the material objects but replicated parts of the original model from the moulds. The use of imaging techniques to capture cultural heritage objects is widespread (Payne 2012), with options for both capture and replication being reviewed by Wachowiak and Karas (2009). Balleri and others (2014) report on the use of laser scanning to capture negative moulds to replicate sculptures from the Richard-Ginori porcelain factory in Sesto Fiorentino, Italy. Moulds from terrain models would however provide the additional interest of studying their relationship to the geographical spaces they represent and the level of detail adopted. A thorough review indicates that no research featuring the reconstruction of landscape models from negative moulds has been published. The research presented here therefore represents a unique example of digital reconstruction in that it focusses on exploring an historical relief model from a set of negative moulds and other objects related to its construction and context of display.

The strategy for the research was to gather historical evidence about the model to develop a deeper understanding of its creation, physical extent and detail, and its role as a visitor experience. A procedure for digital processing was developed to undertake a spatial audit of the moulds and to reconstruct elements of the model to present its detail to modern day visitors. A public exhibition was designed to engage visitors in this reconstruction process and to allow reflection on the virtues of physical relief models and their relevance to modern geographic visualisation.

\section{Mayson's Ordnance Model of the Lake District}

Up until the start of this project very little was known about the Mayson model, however the discovery of the negative moulds offered a starting point for a new investigation and the search for any other historical evidence began. A letter in Sheetlines, the journal of the Charles Close Society which focusses on the study of 
Ordnance Survey Maps, mentioned Michael Moon, a local bookseller, who had cleared the Mayson building in the late 1970s (Hodson, 1995). Through this contact a number of other historical objects were acquired for the project including: posters used to advertise the model; a letter commissioning the model; original Ordnance Survey maps used during construction; and a sample model tile measuring 1 foot square.

\subsection{Context of display}

The first poster to emerge (Figure 2, left), which measured $32 \mathrm{~cm} \times 44 \mathrm{~cm}$, provided a rich summary of the model and its context of display. The poster confirmed that the model had been based on the recently published Ordnance Survey six inches to the mile maps and used this prominently in advertising, the poster reading "The model has been constructed mathematically from the Ordnance Survey, after great labour and at a heavy cost". Reference is also made to the model being faithful to the survey in all dimensions with "the horizontal and vertical scale being 6 inches to a mile". Suggestions of the model's cartographic completeness are seen, stating that "All the mountains, lakes, tarns, waterfalls, rivers, and their tributaries; woods, roads, villages, villas etc., are correctly delineated".

The poster showed an image of Mayson's building as visitors would have seen it as they moved into Lake Road on their way to a popular 'viewing station' on Derwentwater called Crow Park, a recommended location from which to appreciate the Lakeland landscape. The term 'Lake District Repository' is used to refer to Mayson's building, promoting it as an important source of information for exploring the wider landscape. The poster stated that "Parties visiting this model will see the correct topography of the Lake District, and can thereby readily plan either long or short excursions as time will permit. They will also gain a better idea of the whole of the Lake Country than is to be obtained from any other source". The reference to 'any other source' might include the small maps and vignette drawings in guidebooks that visitors at that time had available to them. It would also refer to the Flintoft model, which had been based on surveys undertaken by one person and was clearly deemed by the Mayson brothers to lack the authority and detail of their model.

Similar information is seen in other larger posters which would have been displayed together in vertical strips at the railway station (recreated in Figure 2, centre), suggesting an active targeting of visitors new to the town. The banner 'For trustworthy information visit the Ordnance Model' draws upon the governmental military survey to add authority to help justify the model as a visitor experience worthy of a one shilling admission fee. Another poster (Figure 2, right) refers to the model as the 'only accurate and reliable source of information', and makes another clear reference to the Flintoft model with the claim of it being " 4 times the size of any other model exhibited".
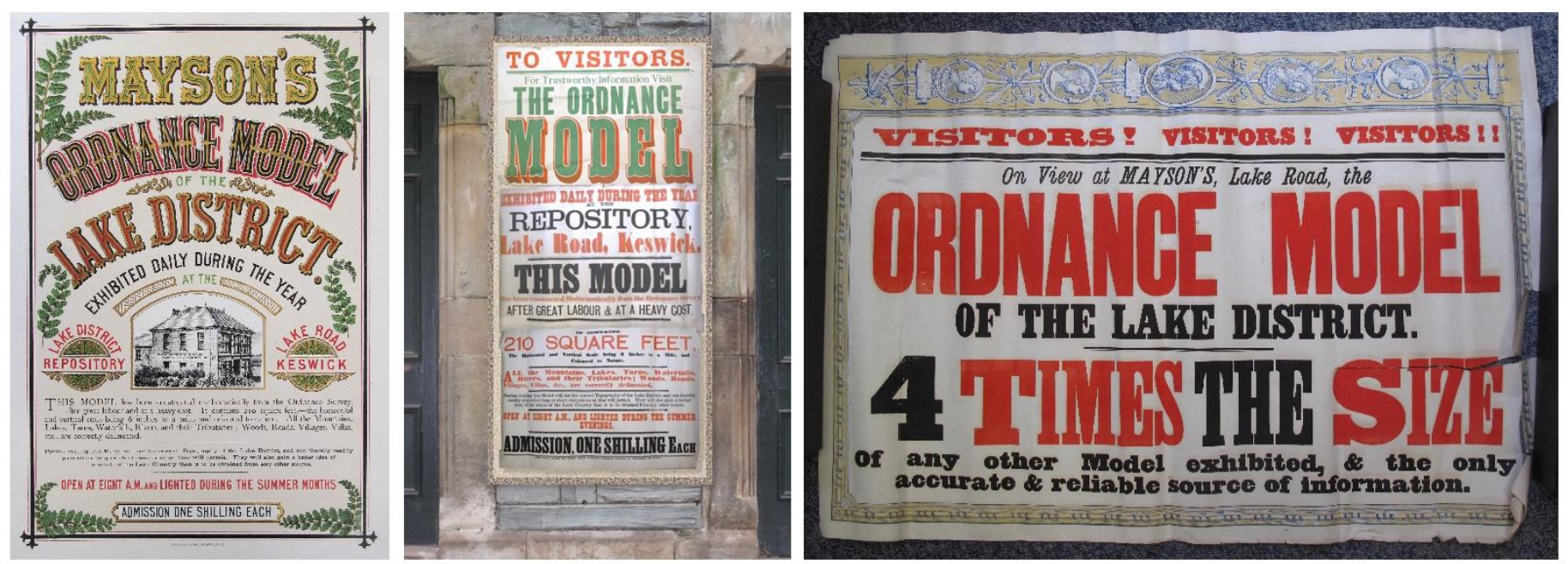

Figure 2. Posters Advertising the Model. Photographs by the author. 
The letter commissioning the model references Ordnance Survey map sheets covering the central Lake District, whereas the Flintoft model extended to cover much of the coastline as shown in Figure 3. At a scale of 6 inches to the mile instead of Flintoft's 3 in inches to the mile the Mayson model was 210 square feet in area compared to around 75 square feet of Flintoft's, somewhat less than the ' 4 times the size' stated in the poster.

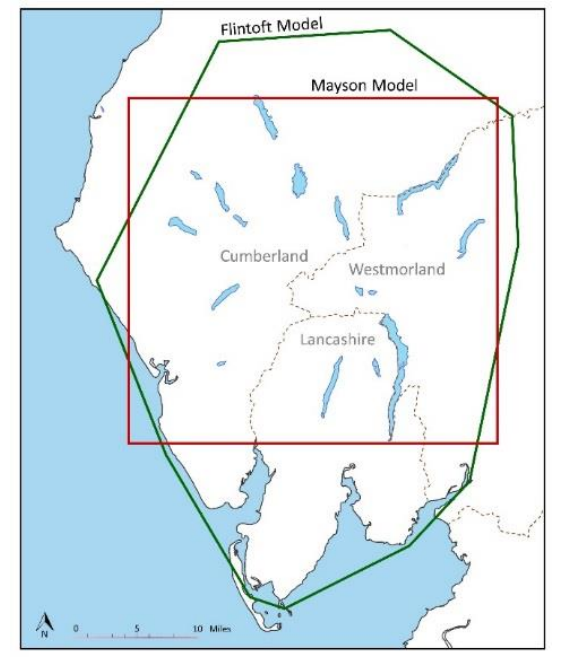

Figure 3. Comparison of the geographical coverages of the Mayson and Flintoft models.

The letter of commission was originally signed on the $19^{\text {th }}$ January 1875 and stated a target for delivery of $28^{\text {th }}$ March 1875 but the letter was updated in July of that year with a new target of $5^{\text {th }}$ August 1875 . It is unclear when the model was finally completed but archival searches reveal the first reference to the model in local newspapers to be on Friday 19th May 1876 in the Carlisle Journal reading "NEW MODEL OF THE LAKE DISTRICT - Messrs. Mayson Brothers have, with praiseworthy enterprise, just opened a new model of the lake district on the Ordnance Plan, in the Lake Road, Keswick. The model claims especial notice for its good execution and minuteness of detail, presenting at one glance to the spectator a most comprehensive view of the mountains, lakes, tarns, forests, towns, roads, rivers, castles, and all that is noteworthy in the district. It is upon the scale of six inches to a mile, and, as explained by that intelligent cicerone Mr. Thomas Mayson, is a veritable vade mecum to the stranger in Lakeland." The term 'vade mecum' is used to promote the model as an indispensable guide for the visitor.

Throughout the summer of 1876 regular advertisements for the model can be seen in local newspapers including the Carlisle Express and Examiner, the Cumberland and Westmorland Herald, the Lakes Chronicle and Report, and the Northern Counties Gazette. On Saturday 26th May 1877 the English Lakes Visitor and Keswick Guardian was launched to target the growing number of tourists arriving in Keswick and the Mayson brothers ensured their model was advertised in the first issue and then at regular intervals for several years. The posters suggest that Mayson initially charged one shilling (equivalent today to between $f 8$ and $f 10$ ) for entry to his studio to see the model but later reduced the price of entry and finally removed the entrance fee altogether.

In 1878 the Keswick Literary Society purchased the Flintoft model for their recently established museum in the centre of Keswick and in the same year leased the museum to Thomas Mayson for a period of five years (Bott, 1994). There is evidence that Flintoft had attempted to sell smaller versions of his model via a subscriber's book, now in the Carlisle Archive Centre, and in 1881 Mayson took over the book, but referencing the Ordnance model instead. This, along with posters advertising both models and Mayson's photographic services, suggest that the Mayson model continued to have an important commercial value well into the 1880s. In fact in 1889 newspapers record that George Abraham, a rival photographer also on Lake Road, built a landscape model based upon Ordnance Survey maps, though no further evidence has emerged relating to 
this endeavour. It does suggest however that towards the turn of the century in Keswick landscape models were seen as an important device to attract the attention of tourists in order to sell photographs, and later postcards.

\subsection{Creation of the Model}

The commissioning letter reveals that the Mayson brothers and London-based Italian sculptor Raffaelle Monti devised a process whereby the model would be constructed from Ordnance Survey maps in blocks, where a block corresponded to a single map sheet measuring three feet by two feet, covering an area of six miles by four miles. The letter refers to twenty five blocks which would represent 150 square feet although the posters describe the model as comprising 210 square feet. There is no evidence to clarify whether the contract with Monti was limited to this set of maps or whether a further contract covering the remaining blocks was arranged. What is clear however is that the letter of agreement gave the Mayson brothers the 'right of reproduction' and prevented Monti from engaging in any further model making activity that might provide competition to the Mayson model. There is no evidence to suggest Monti produced any other relief models, having been known mostly for producing marble figures including the 'Veiled Vestal' in 1847, with the Mayson model commission coming very late in his career.

The creation and storage of a set of negative moulds is considered to be a most unusual aspect of this model making endeavour and their recovery has contributed the most significant body of evidence for this study. The letter documents the intent of the Mayson brothers "Of each of the blocks beside the finished model a set of perfect moulds for future use is to be supplied and this is included in the price".

The recovery of the moulds from storage came about through discussions with the collections officer working for the museums in both Workington and Keswick. The moulds were under the care of the local authority (Figure 4, left) but were not accessioned to the collection of either museum. They were moved to the University of Nottingham in order to be cleaned and a photographic inventory of the 142 moulds was made.

The majority of moulds had become separated from their original side panels, as with the collection in Figure 4 (centre), though some still had four removable side panels (Figure 4, right) which would have held a reservoir of plaster had a positive model been cast from it. Some of the side panels were marked up with Roman numerals indicating the original OS map sheet to which they related, but the majority of moulds lacked side panels and any indication of map reference.
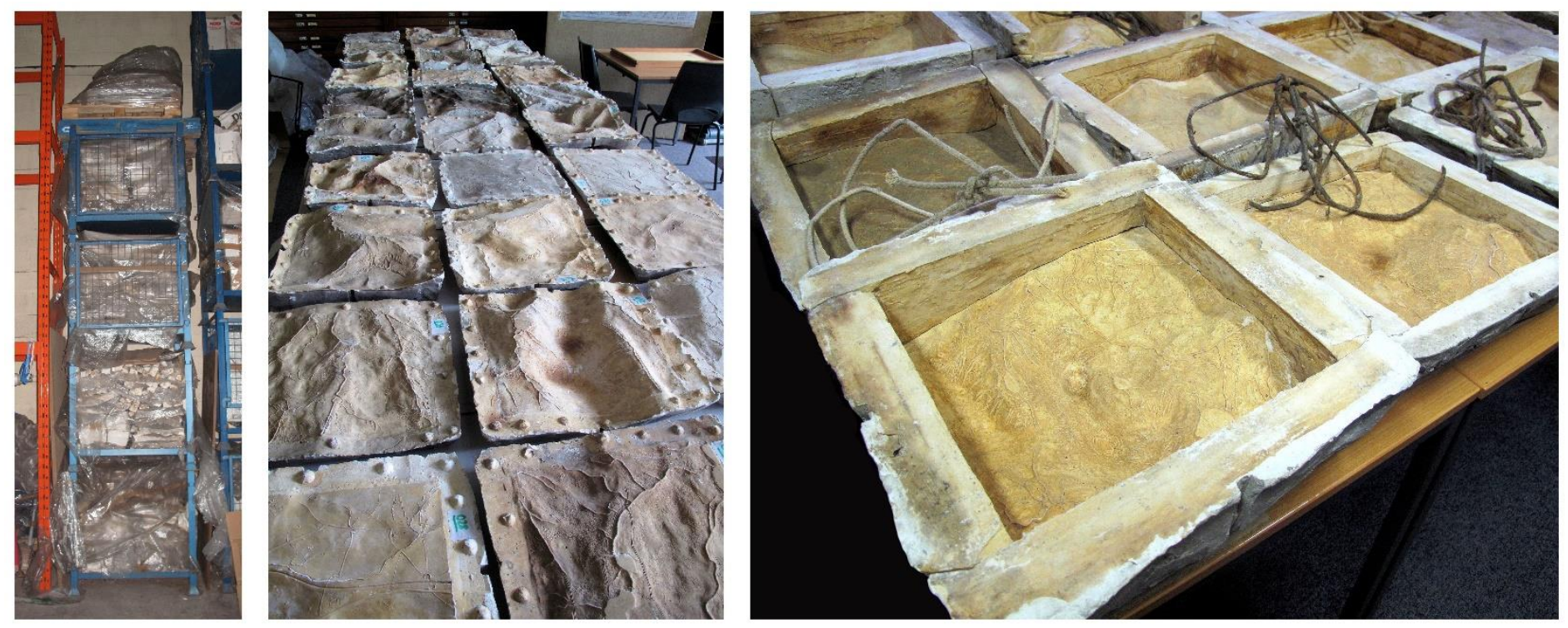

Figure 4. Moulds from the Mayson model in storage (left), some lacked side-panels (centre), some with original side-panels (right). Photographs by the author. 
A number of original Ordnance Survey maps used to make the model provided some interesting clues as to how the model might have been constructed. The maps measured one square foot meaning each original Ordnance Survey block had been physically cut into 6 and these became the individual building blocks with which the model was constructed. The majority of the 103 maps that survived have contours marked up in colour, as with the example in Figure 5 (left), at intervals of 100 feet below elevations of 1000 feet and 250 feet at higher elevations. This along with signs of subtle horizontal banding on some of the mould surfaces indicate that the model making process utilised the contours in some kind of layering process.
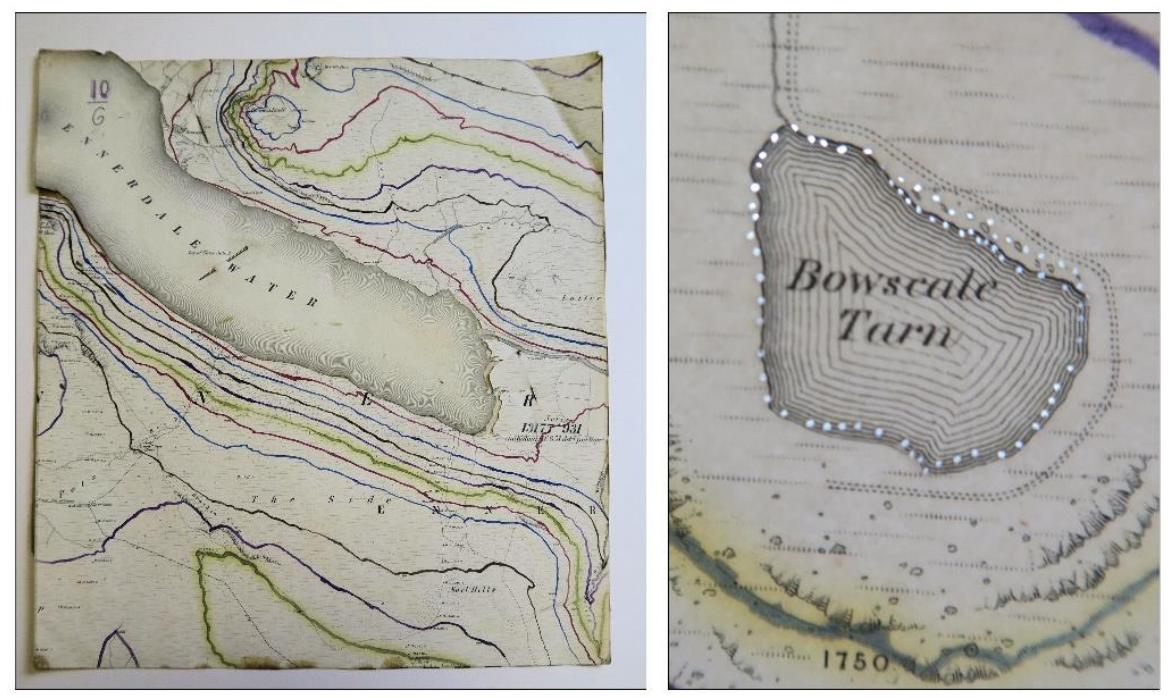

Figure 5. Example of map sheet with contours highlighted (left). Example of pin holes used to transpose the location of small features (right). Photographs by the author.

Large water bodies were usually cut out as in the case in Figure 5(left) and the locations of small water bodies and settlements were marked by pin holes as seen in Figure 5 (right). This suggests that the position and geometry of many cartographic features from the maps were captured directly during the model making process.

Comparing the maps with their equivalent mould surfaces reveals that a particular symbol set was used to mark out features. Figure 6 shows a mirrored image of an area of mould surface 4 inches by 4 inches centred on the town of Windermere, indicating how this symbol set would appear on the positive model before final texture and colour was added.
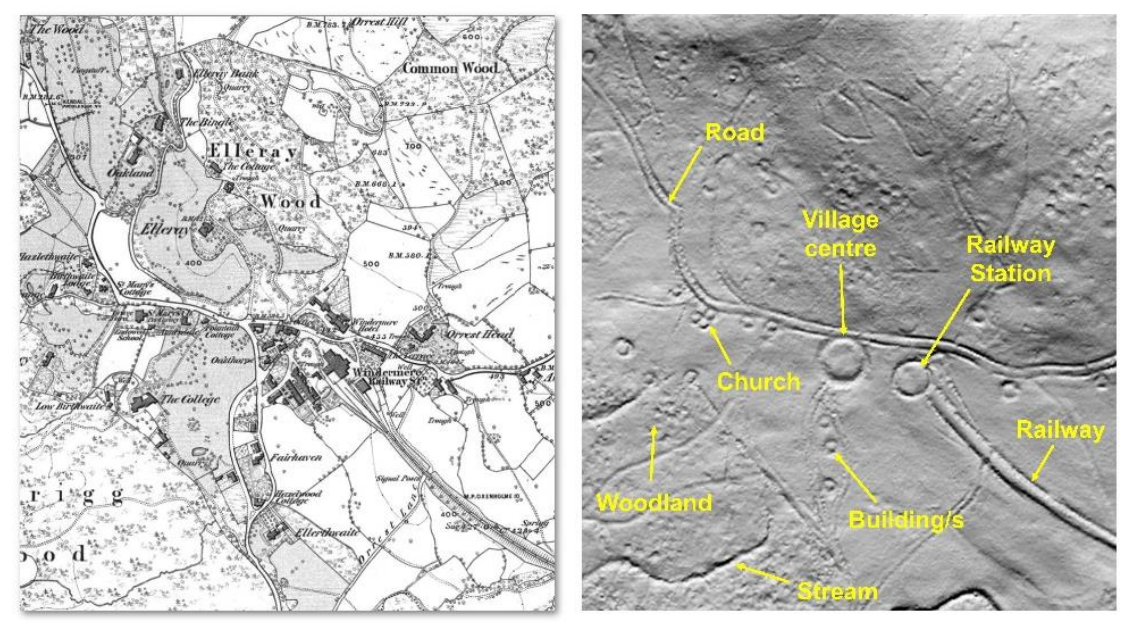
Figure 6. Ordnance Survey map from 1862 (left); Mirror image of the mould surface showing symbol set (right). Images by the author.

There is no documentary evidence to confirm the detailed stages of the model making procedure, though from the evidence provided by the maps it seems likely that the contours were transferred to wooden layers. Surface markings on the negative moulds suggest that sculpting tools were used to add detail to the general form of the land, perhaps on clay worked over the wooden layers. It is onto the clay positive models that the detailed cartographic features described earlier could have been transcribed. Negative moulds could then be produced and from these positive plaster models cast. The generalised stages of model making for a single square tile are shown in Figure 7. Räber (2006) and Imhof (1981) describe the more detailed stages of layer based relief model construction that have been documented by Swiss model builders from later in the nineteenth century onwards.

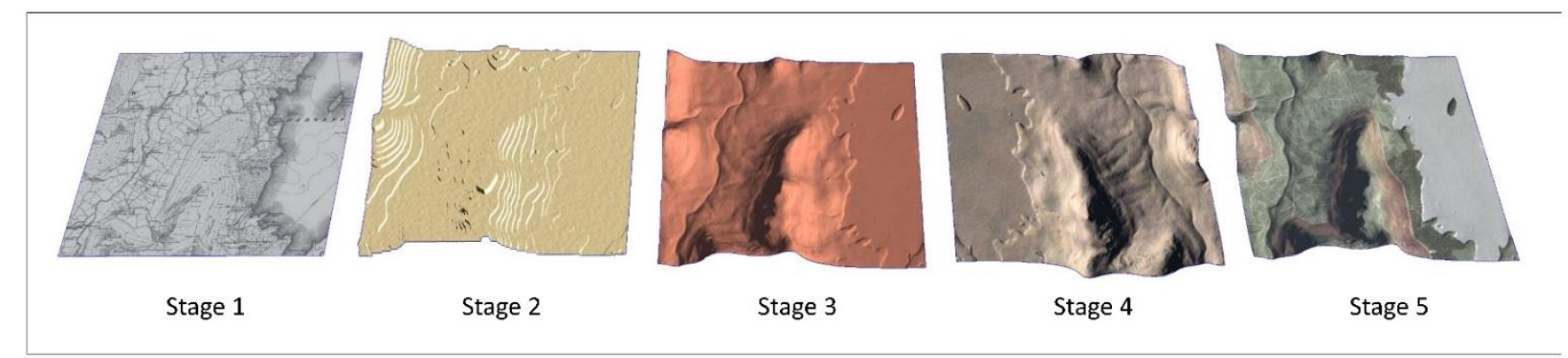

Figure 7. Likely stages of the modelling process, left to right: Paper map, Layered wooden model, Clay model, Negative Mould, Positive painted plaster model.

The individual square models were joined into blocks of six corresponding to the original OS map sheets. The cost of the whole process is stated in the letter as being $£ 362$ and 10 shillings with the painting of the model being a separate arrangement with a $\mathrm{Mr} \mathrm{H}$. B. Hayes costing an additional $\mathrm{f62}$ and 10 shillings.

As with the majority of landscape models the Mayson model was 'coloured to nature' as the poster described it. This style of modelling would later be referred to as 'naturalistic' by Curtis (1911) when describing the models of Edwin Howell, which contained "all the data of the relief map and much more in addition".

The discovery of a single positive tile in a custom made wooden box, likely to have been produced as a sample of what the model would look like, provided some evidence of how the final Mayson model would have been finished (Figure 8). In addition to indicating the colours and textures used for the landscape surface it also suggests that the circular symbols seen on the moulds were used as markers over which simplified building objects were added and painted on the final model blocks. There was an inevitable level of generalization compared to the high level of detail in the Ordnance Survey mapping, with buildings being grouped into a smaller number of larger objects.

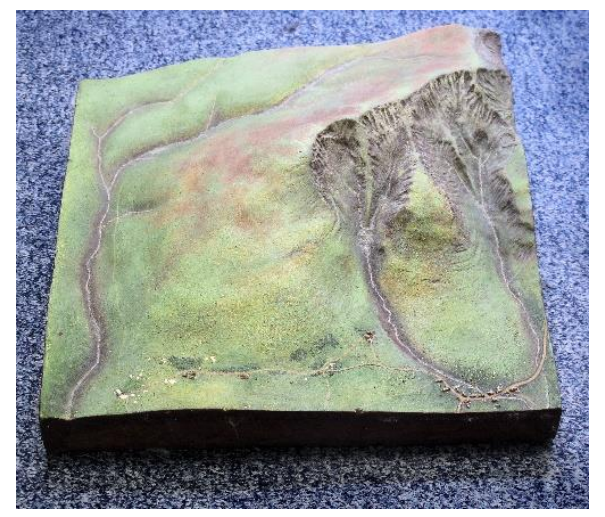


Figure 8. Original sample tile from the model. Photograph by the author.

The resulting model measured 15 feet or $4.57 \mathrm{~m}$ (east-west) by 14 feet or $4.27 \mathrm{~m}$ (north-south). A digital reconstruction of what the model may have looked like when displayed is shown in Figure 9, using the openly available 'Terrain 50' data from Ordnance Survey to create the surface model.

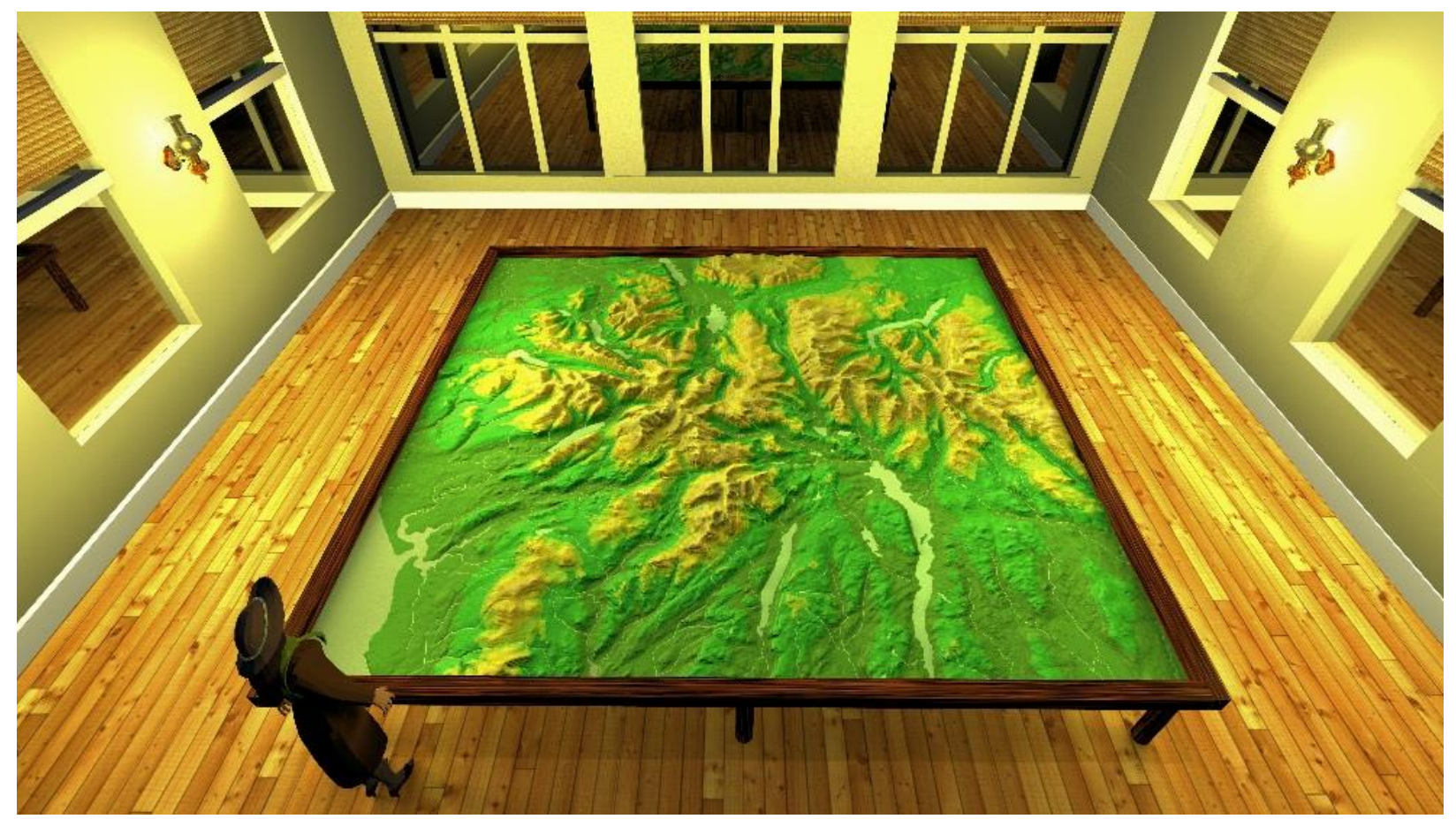

Figure 9. Digital Reconstruction showing the Mayson model displayed in Lake Road Studio

The moulds from the Mayson model contained a vast amount of information and in order to study the detail and to establish their spatial reference a process of digital capture was designed. This would also allow selected moulds to be digitally inverted in order to give an impression of what parts of the final positive model might have looked like.

\subsection{Digital Capture of the moulds}

There was a desire to have control over capturing all surface features as accurately as possible and a handheld 3D laser-scanner was considered appropriate. The digital surface models that resulted from the scanning process would allow various forms of manipulation within a Geographical Information System (GIS) such as the production of hill shade images to reveal subtle surface details. The procedure for digital capture and processing is summarised in Figure 10. 


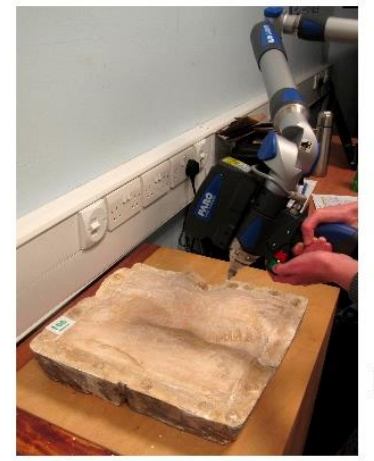

Laser-scanning of negative mould to produce point cloud

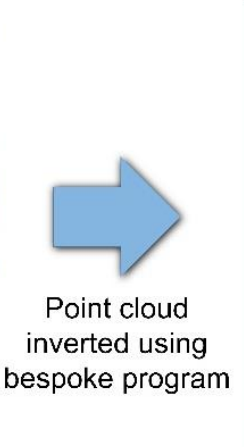

Figure 10. Overview of the digital capture and GIS-based processing.

Each mould was scanned in turn using a FARO Laser ScanArm V3. A series of partially overlapping scans built up a complete point cloud representing each mould surface along with the edges which would have held the side panels. The point clouds were tidied within the PolyWorks software before being exported as text files containing $\mathrm{XYZ}$ point coordinates. A bespoke computer program was written by the author to invert the $X Y Z$ format point clouds which were then imported into ArcMap where they were converted to Triangular Irregular Network (TIN) mesh structures, then to grid-based Digital Surface Models (DSM), and finally to hill shade images which represented the positive surfaces as if cast from the moulds.

The first stage of identifying the grid squares to which the moulds related involved comparing the hill shade images with a large base map made up of a modern hill shade image overlain with water features and the grid squares relating to the Mayson tiles. The orientation of the moulds in relation to the map was not known so the matching procedure was time consuming. There were 67 moulds identified during this stage and it became obvious that this task was highly effective in promoting an understanding of how landscape features had been represented on the model. It was felt that there was an opportunity to involve the public in this process as part of a wider effort to engage the public in the story of the Mayson model.

Given the connections to Keswick there was great interest from the curator at Keswick museum in hosting some form of exhibition to showcase ongoing work on the Mayson model. Fortuitously the museum had been closed for refurbishment and a schedule for new exhibitions was being planned. An exhibition based upon the Mayson model was factored in for early 2015, the year after the re-opening of the museum.

\section{Re-engaging the public with the Mayson model}

\subsection{Aims of the exhibition}

In planning a public exhibition a set of aims were developed in terms of what visitors should gain from the experience. Given that the model no longer exists there was a challenge in conveying the physical form of the object. It was also recognised that it would not be possible to replicate the impact the model might have had on visitors to Keswick in the nineteenth century. It was therefore decided that the focus would be on conveying the innovation of the Mayson model and to raise awareness of modern day modelling techniques, giving an opportunity to explore how relief models function in the context of a visitor experience today. To reflect the overriding theme of exploring 'technologies' old and new that offer privileged aerial perspectives of a landscape, the exhibition was titled 'The Grandest Views: Models of Lakeland from Victorian Times to the Present Day'.

The aims of the exhibition were to convey:

- Historical context - present the background to the model's creation 
- Physical form - convey the size of the original model and the surface detail

- Function - how the model worked as a visitor experience

- Innovation - convey the innovation of contours and the modelling process, set against modern methods for creating and visualizing the landscape.

- Process of research - engage visitors in the underlying evidence, in particular the moulds, by inviting them to locate the remaining moulds on the map

The exhibition ran from $7^{\text {th }}$ February to $17^{\text {th }}$ May 2015 within the gallery space at Keswick Museum. The museum, which opened in 1898, boasts a diverse collection drawing upon connections between natural history, industrial heritage, local characters, and the cultural heritage of the northern Lake District. It attracts a diverse range of visitors including tourists and local residents but also hosts school groups and college fieldtrips, with educational activities linked to the main collection and any exhibition being held in the gallery space. Since 2014 the Flintoft relief model has been mounted on an end wall, space restrictions preventing it being horizontal as originally intended. The typical visitor flow sees people tour the main collection first so the majority of visitors would have seen the Flintoft model before entering the gallery space.

\subsection{Exhibition Design}

The arrangement of some of the key elements of the exhibition is shown in Figure 11. The background to the creation of the Mayson model was presented through a number of information panels along with related historical objects in a cabinet, though care was taken not to rely on a sequential narrative around the space. Separate elements were designed to stand alone but contained connections to related elements elsewhere in the space using text captions or other aspects of their content.

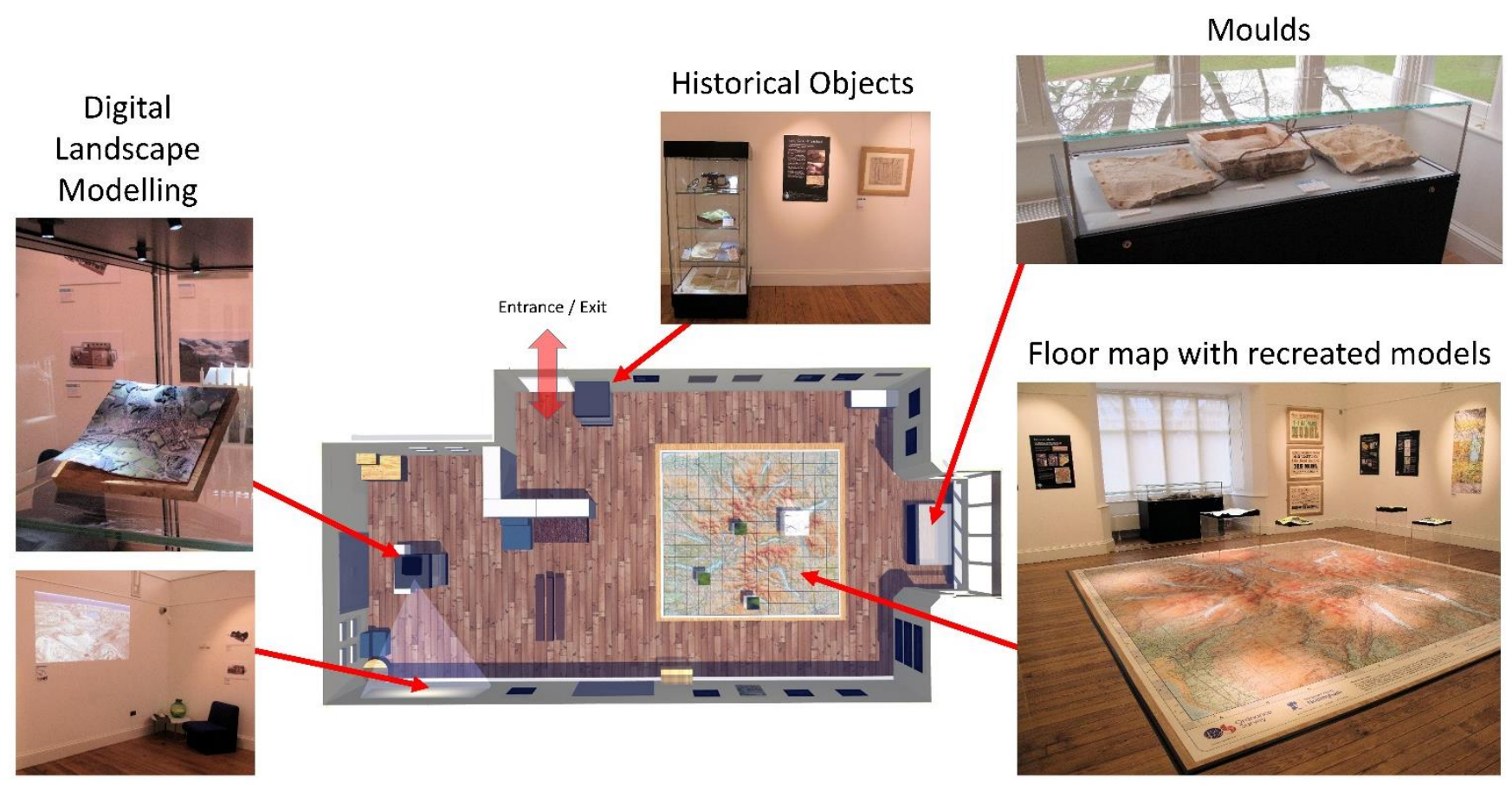

Figure 11. Gallery plan and the arrangement of the key elements of the exhibition.

The recreation of a full sized physical replica of the Mayson model was not possible given the time and resources available. In order to convey the size of the model therefore, in addition to the digital reconstruction image (Figure 9), a floor map was designed at the scale of the Mayson model. Whilst this could not replicate the visual presence of a large physical model it did offer some of the functions for orientating visitors. The 
design of the map attempted to convey relief in a clear and engaging fashion and its physicality meant visitors had to move around it to appreciate the detail. A custom backdrop for the map was created comprising a hybrid of a hill shade image and a conventional colour ramp of relief bands, both derived from Ordnance Survey 'Terrain 5' data. This was then layered behind the modern 1:50,000 scale map by Ordnance Survey cartographers to produce something that was familiar to many visitors but with an enhanced relief effect to provide a clearer impression of topography from a distance. Taking inspiration from previous best practice, as encouraged by the cartographic review of Demaj and Field (2012), the design aimed to achieve the combination of information content and beauty of relief portrayal seen in the Ordnance Survey 'Tourist' maps of the mid twentieth century.

In attempting to convey the detail of the original model, three one foot square tiles focussing on areas of interest were recreated through digital 3D fabrication and mounted on clear plinths over the floor map above the appropriate grid square. The digital capture process had produced a Digital Surface Model (DSM) for every mould, representing a positive model as if cast from the negative mould. For the three tiles selected for recreation further GIS-based processing was required to transform the DSM onto the modern Ordnance Survey National Grid to establish whether there was a systematic tilt within the data. It was evident that the moulds had been designed to 'sit flat' on a surface so the top of any plaster reservoir would form a horizontal base for a positive model tile. This could not be relied upon however due to damage to the underside of many of the moulds. Any tilt identified in the DSM was corrected before exporting the data via a TIN to a VRML format for input into the CAD software used in 3D fabrication.

The use of a subtractive computer numerical control (CNC) milling technique was deemed suitable given the nature of the surfaces involved, there being no requirement for producing complex 3D geometries with overhangs as would warrant additive 3D printing. The mesh was processed within the Rhino software, then transferred to MasterCam to produce toolpath files which controlled the path of the drill which carved the surface from model board in several passes (Figure 12).

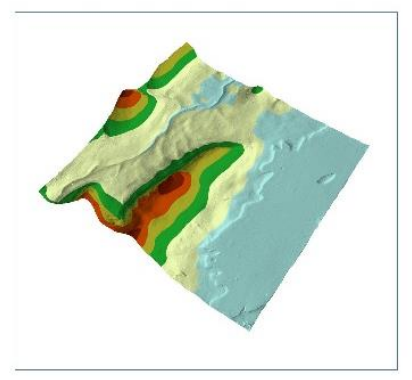

TIN exported from ArcGIS as VRML file

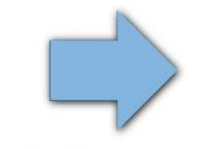

Mesh converted to CNC milling paths in Rhino and Mastercam
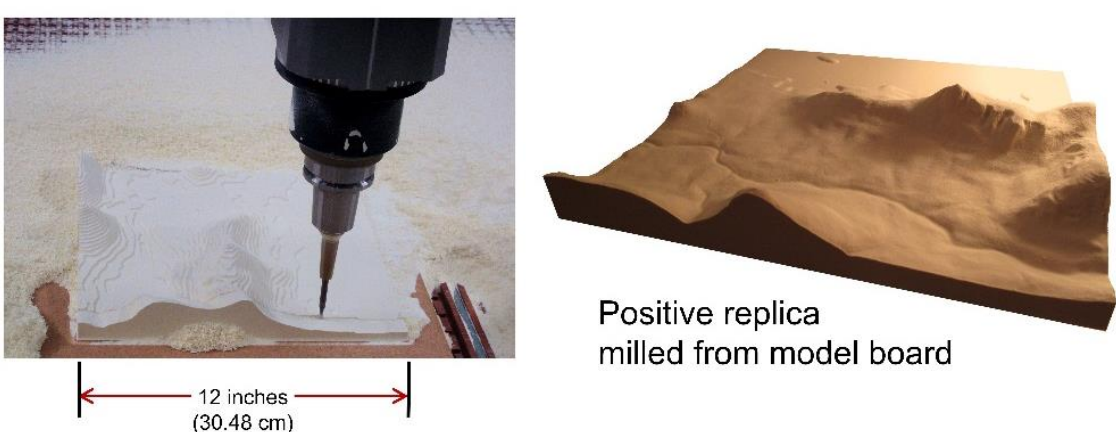

milled from model board

Figure 12. The digital stages of 3D fabrication

Each model was then hand crafted by the author using epoxy putty to add texture and acrylic paint to add colour, using the surviving Mayson tile as a guide. Figure 13 shows the models as they appeared above the floor map. The first replica model featured the 'Langdale Pikes', a recognisable location popular with walkers and climbers. The second model featured landscape change focussing on the expansion of the towns of Windermere and Bowness, the centres for tourism in the southern Lake District. The third model focussed on a valley called Mardale which was flooded to form the Haweswater reservoir just over 50 years after the model was constructed. 

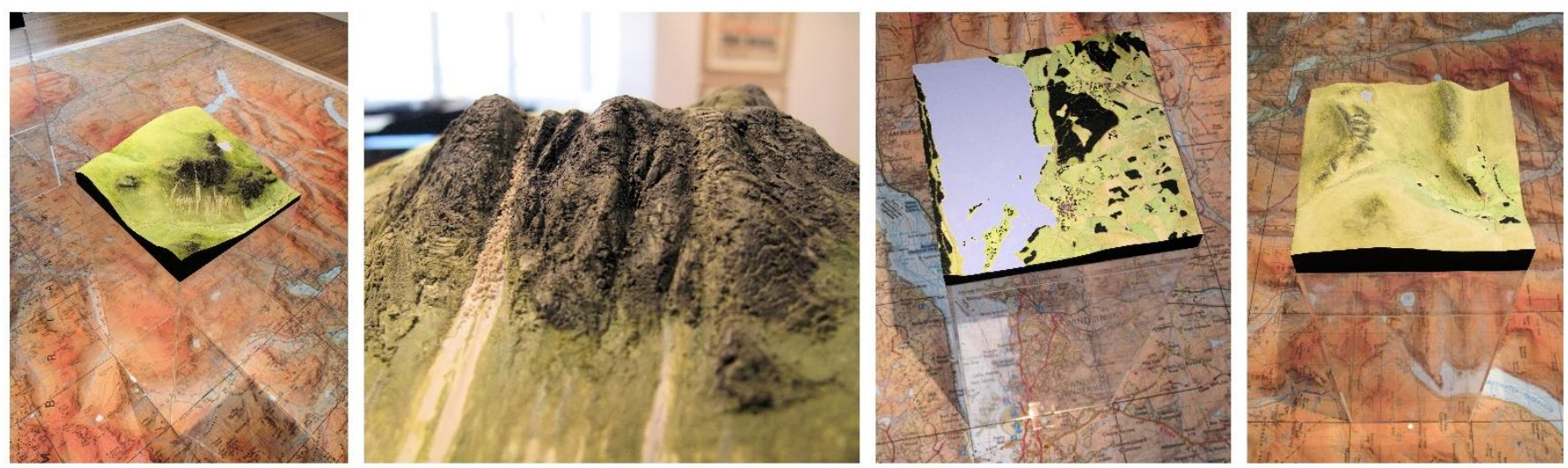

Figure 13. Replica tiles (left to right): The popular fells of Langdale; Detailed rock texture in Langdale tile; Urban expansion around Windermere; The flooding of Mardale with Haweswater.

The aim of the original model was not only to captivate and impress visitors but to provide them with a clear frame of reference against which to gain an understanding of the landscape around them and perhaps plan a journey. The floor map performed some of this function, complemented by 'map explorer factoids' posted on the wall asking visitors questions where the answers were places to be found on the map. The original model would also have offered some of the functions of a 'You-Are-Here' style map. In the exhibition a Projection Augmented Relief Model (PARM) display (Priestnall and others 2012) shown in Figure 14, was placed over the floor map comprising four replica tiles centred around Keswick, painted white to enable projection. The display animated the arrival of early tourists via the railway, their movement down past the museum (the visitor's current location), past the Mayson building and on to the Crow Park viewing station on the shores of Derwentwater.

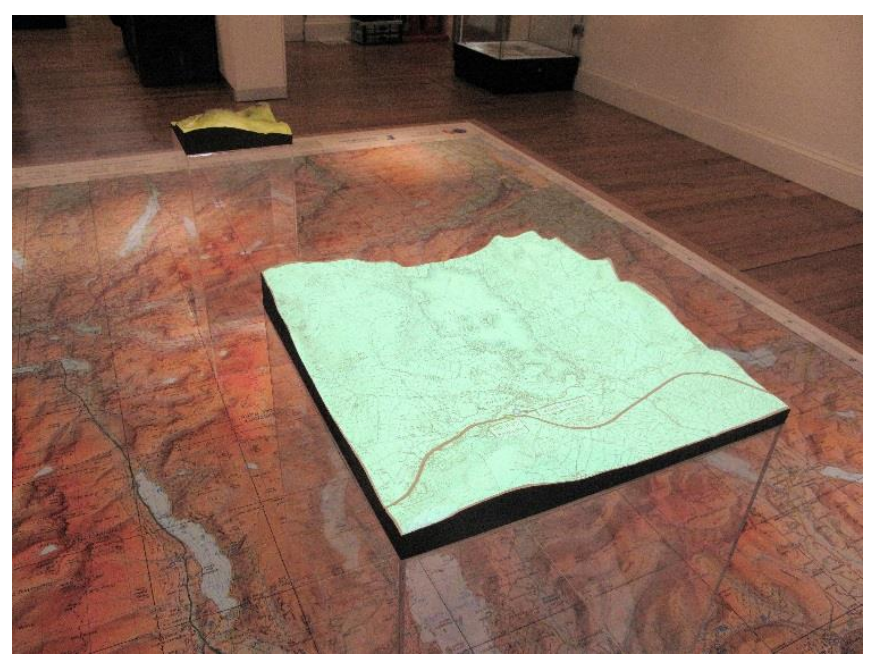

Figure 14. Set of four replica models enhanced through projection. Photograph by the author.

The innovation of the Mayson model and the advances in map making that had enabled its creation were conveyed through a combination of historical objects and the painted replica models which allowed close inspection of the likely level of detail. Elsewhere in the gallery space were exhibits showing the capabilities of digital landscape modelling including a virtual fly-through visiting the locations featured in the replica tiles and examples of 3D printed landscapes. One message that was key to the exhibition was that despite the many capabilities of modern digital landscape modelling techniques they still struggle to provide such clear and engaging overviews of landscapes as offered by physical relief models.

An important aspect of the exhibition was to give visitors an opportunity to engage with part of the research process by attempting to match mirrored photographs of the so far unreferenced moulds with a square on the 
floor map (Figure 15). Over the course of the exhibition a further 55 moulds were successfully referenced to the map, adding to the 67 already identified. This activity proved very popular and was evidenced by many longer than average visits and repeat visits.

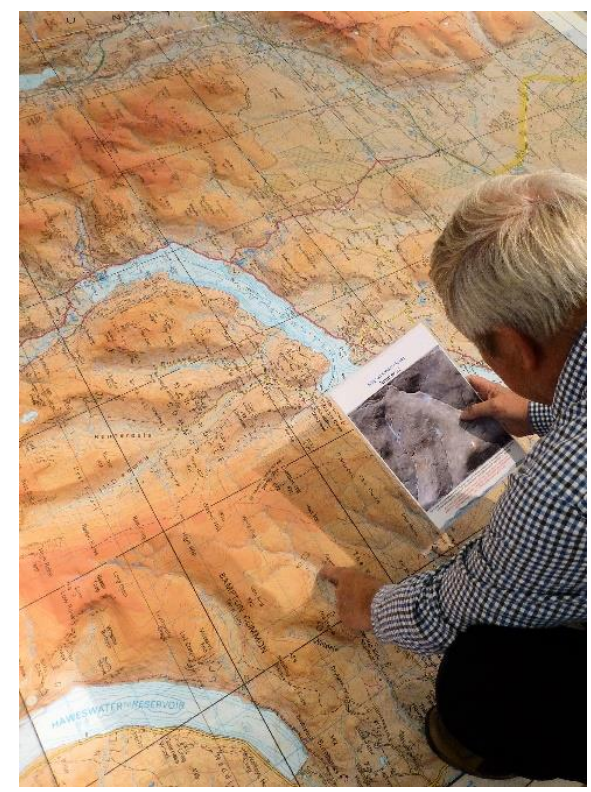

Figure 15. Visitor-led search for the map references for the remaining moulds. Photograph by the author.

After the exhibition 20 moulds still lacked a spatial reference so the hill shade images of these tiles were systematically checked off against the map squares that had yet to be allocated a tile. Once all of the moulds had been allocated to a grid square, and therefore their orientation was known, a complete set of new hill shade images was produced using a consistent direction of light coming from the North West. Figure 16 shows a mosaic of all the hill shade images of the digitally inverted moulds and offers the best impression of the model's surface possible from the evidence available. The letter of commission referred to 25 map blocks each of which was cut into 6 squares, which would mean 150 moulds. It seems likely from the mosaic that the 142 moulds are a subset of the 150, indeed the 103 map squares recovered also fall within this area. No evidence was found to account for the additional 60 squares that would complete the 210 square feet model described in the posters. Whether they were the subject of a separate agreement with Monti or whether the Mayson brothers completed the model in some other way is unknown. 


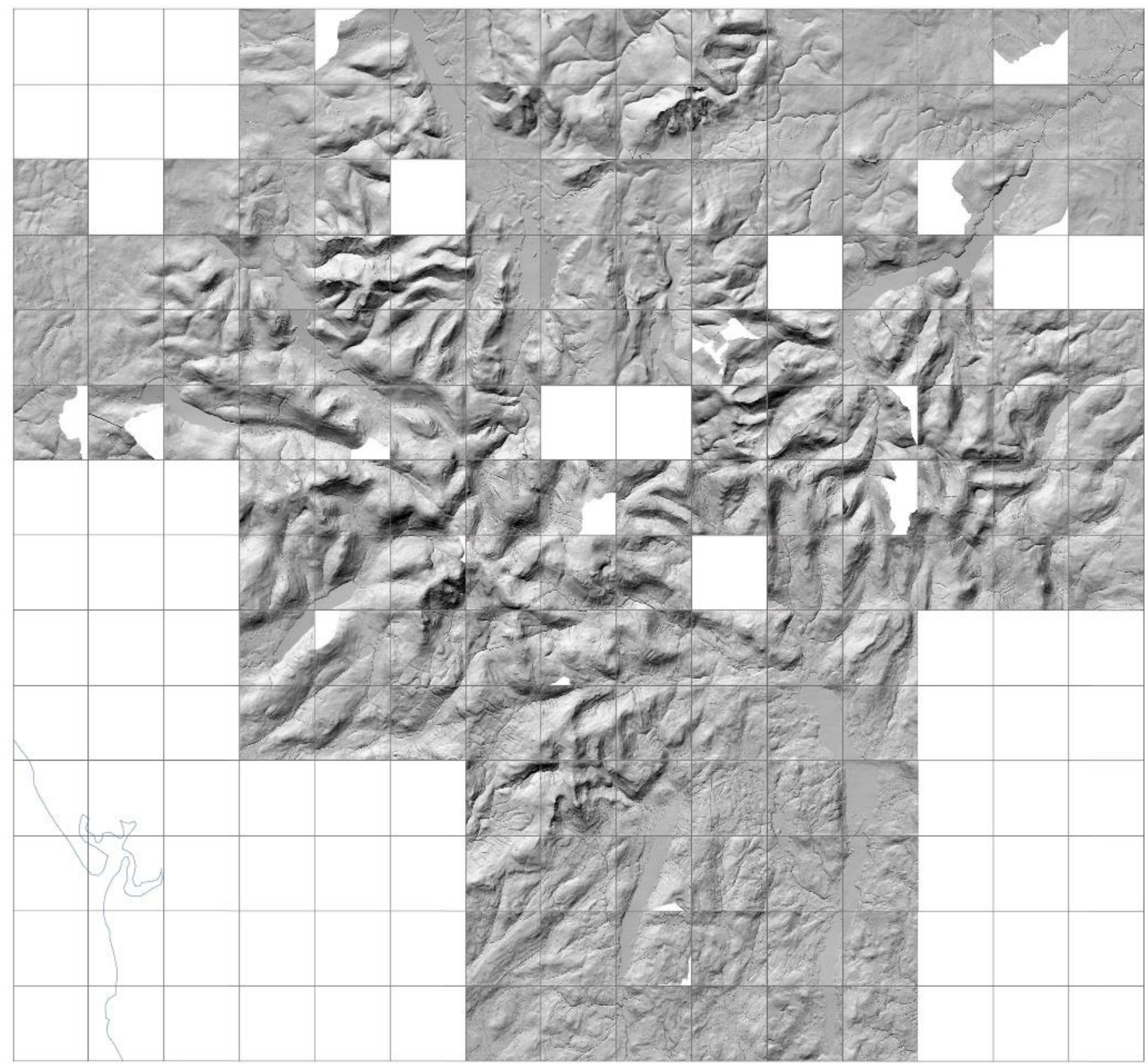

Figure 16. Mosaic of hill shade images from the full set of digitally inverted moulds.

\subsection{Visitor reaction}

Visitor reaction to the exhibition was hugely positive and it was clear from direct observation over many days that visitors were attracted specifically to the models, and this evidenced in comments in over a quarter of the entries in the museum visitor book, with over a third mentioning the exhibition in general. Comments were also in evidence relating to the process of model making, the capabilities of new technologies and the process of research and reconstruction. There was an appreciation of the importance of early cartographic innovation with two separate but almost identical comments suggesting 'we owe them so much'.

Observations in the gallery revealed many patterns of visitor engagement with the exhibits. The typical trajectory was to enter the space and move to the edge of the floor map and survey the area before moving towards one of the detailed models or the PARM display. This was most often followed by movement back to the first information panel or display case to discover the background. The floor map and detailed replica models proved successful in providing some degree of 'wow' factor, often accompanied by the identification 
of a recognisable place which would invariably result in movement around that model or place on the floor map whilst someone explained the significance of that place to others in the group. This combination of physical interaction and storytelling was evident in the majority of visitor groups.

Engagement with the exercise of locating the remaining moulds on the map was strong. As well as direct observation this was evidenced by many emails conveying the hours spent, often unsuccessfully, attempting to match a photograph of a mould with the map. As well as the attraction of this geographical jigsaw puzzle, this proved a successful way of engaging people with the detail of the model and the process through which map features had been transcribed onto the model.

\section{Discussion}

The exhibition did not attempt to reconstruct the Mayson model in its original and complete form and could not replicate the role it played in the visitor experience in the nineteenth century when maps and aerial perspectives were less common. Today maps support our orientation and navigation via smartphones, aerial overviews are common in the media, and earth observation provides imagery from satellites, aircraft and more recently drones. That said, visitors still appeared to be fascinated by relief models, even when placed alongside digital representations of landscape.

The apparent power of models is seen across a range of disciplines, helping people develop understanding through rich bodily engagements involving touch, discussion and movement around the model. In reviewing the role of solid models across the sciences de Chadarevian and Hopwood (2004) suggest that "By studying their making, distribution and display, we learn more about models, about representation and dimensionality, and about producing knowledge" (p14). In such a way the exploration of the Mayson model has offered an opportunity to reflect not only upon its construction and physical characteristics but on the ways in which it functioned as a visitor experience. The discovery of the negative moulds led to a unique investigation combining historical research, digital reconstruction, and public exhibition, allowing the significance of the Mayson model to be fully explored.

Before the Mayson model the majority of landscape models were made to support military decision making. Notable exceptions were the models by Pfyffer and Flintoft which promoted an awareness of the surrounding landscape for a broader audience. The Mayson model was however an even more explicit example of a visitor experience built specifically to exploit the financial opportunities presented by the emerging tourist industry. It was commissioned from a sculptor using government survey data rather than being surveyed and built by the same person. It was an investment designed to promote the sales of Mayson's photographic services as well as generating income through charging for admission. To achieve this the model was advertised as the best way for visitors to plan their journeys from Keswick. As such it represented an early example of a promotional tool, as would be seen later with the model of Jungfrau by Xaver Imfeld being used to promote the new railway in 1900 (Pearson, 2015).

The Mayson model was also significant in the way technology and innovation played such an important role in both its creation and advertising. The use of the word 'Ordnance' in the name and the references to the trustworthy nature of the information it provided were accompanied by a style of advertising that promoted the model as being both a scientific endeavour and a spectacle. There was a showmanship about the display which played to the public's interest in novelty, science and innovation as seen with the success of scientific shows and exhibitions of the mid to late nineteenth century (Kember and others, 2012). There would have been great competition for the attention of tourists and with postal directories of the time such as Slater's listing four photographers in the town Mayson would see the model display as giving him an advantage. A critical innovation seen in the Mayson model was the use of contour lines present in the Ordnance Survey maps which allowed a detail and consistency of landscape representation that had rarely been seen before. Examples of relief models made from contours date back to 1811 with the French plan-relief representing a small area near La Spezia in Italy commissioned by Napoleon (Warmoes, 2012). In 1853 in Switzerland Karl 
August Schöll produced a relief of the St. Gallen and Appenzell area in northern Switzerland based upon contour lines at the scale of 1:16,000, a much larger scale than was typical at the time. Contour lines were not however present on the first national scale maps in Switzerland, the 1:100 000 Topographic Map of Switzerland (the Dufour map of 1845) which used hatchures. It was not until the 1870 s when the Dufour surveys were revisited, adding detail at a scale of 1:50,000 in the Alps, when contours where used in what was referred to as the Siegfried Atlas. This opened up the possibility of using contours for creating relief models of large areas and a group of modellers known as the 'School of Zurich' emerged. This included Xaver Imfeld who produced contour-based reliefs during his time at the Swiss Federal Topographic Bureau between 1876 and 1888. The fact therefore that the Mayson model was created in 1875 , based on national contour mapping at a scale of 1:10,560, suggests that it was not only a unique local attraction but was innovative in terms of relief modelling internationally.

The mapping used to construct the Mayson model is relatively large scale for relief models of the time and the use of a cartographic symbol set on the moulds helped transcribe detail from the maps to the model. A high level of detail is important, along with realistic colours and textures, allowing someone to view the model as if looking down on a real scene. This was in evidence from the exhibition when many people recognised the 'Langdale Pikes' model on entering the gallery space and moved across to study it. One aspect of the creation of the Mayson model which remains uncertain is whether the actual landscape features were observed directly to inform the detail of the model, given that the model was constructed in London.

The attention to detail shown during the making of the Mayson model came twenty five years before the guidelines for the creation of relief models proposed by Charles Perron in 1900. Ferretti (2014) described Perron's belief that models should represent the Earth as exactly as possible, suggesting they should only depict what is on the ground and be constructed according to 'rather precise mechanical procedures so as to achieve mathematical exactitude'. The reference to the Mayson model being constructed mathematically from Ordnance Survey mapping suggests both model and map were regarded as the results of rigorous endeavour, an example of how topographic survey contributed to a more scientific status for cartography at certain times (Buchroithner and Fernandez 2011). The degree to which the Mayson model was actually mathematically faithful to the original maps cannot be judged with certainty as only negative moulds can be measured rather than the model itself. A future investigation could however adopt similar techniques to those used by Pearson and Schaefer (2009) to check for consistency and accuracy, but using the moulds instead of an actual relief model.

In addition to detail, the size of the model would also have been an important part of the spectacle, with the original filling the field of view of the visitor, offering a sense of visual immersion that digital landscape visualisation often strives to achieve. With the original model the central parts were not physically accessible resulting in a more detached form of observation. Physical movement around the model allows the viewer to change perspective and also to discriminate fine three-dimensional detail and texture, along with subtle differences in slope and elevation. This process of perceiving 'structure from motion' is something digital photogrammetric techniques now attempt to exploit (Fonstad and others 2013) in building three-dimensional models from sequences of images. The importance of this to the way relief models function was in evidence at the exhibition when comparing movements of visitors around the models with the passive observation of the virtual fly-through projected onto the wall. In a similar way the Flintoft model, now mounted vertically on a wall in the main museum space, would typically be viewed from a single vantage point as with a painting on the wall, no longer lending itself to exploration in the horizontal plane.

It seems likely that the skill and artistry seen in hand crafted relief models of the past will become ever scarcer Mair (2012). There does however seem to be an opportunity to capitalise on the availability of digital terrain data and the greater use of 3D fabrication to continue to explore the power of physical relief models as part of the modern visitor experience.

\section{Conclusions}


This study has revealed that the Mayson model had a unique set of characteristics, combining innovation with flair, which set it aside from most other relief models of the time. Firstly it was not surveyed and constructed by the same person as with the Flintoft model and others of the time, but was commissioned as a means to target tourists from the newly built railway. There was a showmanship in the way this investment in a new visitor attraction was promoted which played upon the scientific rigour with which it had been constructed. The use of the contours from the 1;10,560 scale Ordnance Survey maps which had been completed in the 1860s was innovative and came just before contour-based modelling became more common in Switzerland albeit here at scales of 1:25,000 or smaller. The way cartographic detail was transcribed from the maps to the model, along with a model size of 210 square feet, combined to make this a unique relief model. The discovery of a set of negative moulds presented an opportunity to explore the physical form of the model through a novel digital reconstruction process. A public exhibition was curated to both disseminate the research and to add to the author's understanding of how the model may have functioned as part of the visitor experience. Whilst we cannot fully appreciate the original impact of the Mayson model it seems certain that it would have been a remarkably popular and effective visitor attraction. There remains a fascination with relief models today, despite our familiarity with aerial perspectives through varied media sources. There may therefore be an opportunity to take inspiration from the Mayson model and incorporate physical landscape models into the design of modern-day visitor experiences.

\section{Acknowledgements}

Particular thanks go to Sue Mackay, curator of Keswick Museum and Art Gallery, for supporting the creation of the Grandest Views exhibition. Thanks also to the following people at the University of Nottingham: Ian Conway, Joe Bailey, Mike Heffernan, David Matless, Charles Watkins, Stephen Daniels (School of Geography); Katharina Lorenz, Craig Goodere and Robyn Sullivan (Digital Humanities Centre, Department of Classics); Sarah Thomas and James Hazzledine (Centre for 3D Design, School of Architecture and the Built Environment); Terry Moore and Martin Smith (Nottingham Geospatial Institute); Sally Bowden and Lisa McCabe (Centre for Advanced Studies). Beyond the University of Nottingham: Frank Priestnall for support with both research and exhibition setup; Michael Moon (Bookseller, Whitehaven, Cumbria); Andy Steggall, Rob Andrews, Guy Heathcote, Charley Glynn, and Mark Wolstenholme (Ordnance Survey); Stefan Raber (Institute of Cartography and Geoinformation, Zurich); the Keswick Museum and Art Gallery Collections and Exhibition Team volunteers; and Glen Hart, Nicci Tofts, Helen Keogh, Charlotte Stead, Pat Maskell, Richard Bainbridge, and Vivian Russell. This work received support from the AHRC Creative Economy Knowledge Exchange Project "Archives, Assets and Audiences" to enable the laser scanning and processing of the negative moulds from the Mayson model.

\section{References}

Balleri, R., S. Di Tondo, G. Adembri, and M. Gherardelli. 2014. “3D Laser Scanning of historic molds for documenting the Richard-Ginori factory collection." Journal of the American Institute for Conservation 53/3: 145-158.

Billen, R., P. Blain, O. Donneau, S. Habraken, Y. Renotte and M. Van Ruymbeke. 2009. "Virtual model of the city of Liège in the eighteen century - Virtual Leodium." In Proceedings of 3D Stereo MEDIA 2009, International 3D Stereo Film and Technology Festival (3D Stereo MEDIA), ed. J. Verly. Lièg, Belgium, 1-3 Dec. 2009. 
Bradshaw, G. 1863. Bradshaw's Descriptive Hand-book of Great Britain and Ireland. Reprint, Oxford: Old House Books and Maps, 2012.

Bott, G. 1994. Keswick: The story of a Lake District town. Cumbria County Library

Buchroithner, M. 2012. True-3D in Cartography: Autostereoscopic and Solid Visualisation of Geodata. Berlin Heidelberg: Springer-Verlag.

Buchroithner, M. and P. Fernandez. 2011. "Cartography in the context of sciences: theoretical and technological considerations." The Cartographic Journal 48: 4-10.

Chevrier, C., K. Jacquot, and J. P. Perrin. 2010. "3D modelling of a town scale model." In Proceedings of the Third International Conference EuroMed 2010 Dedicated to Digital Heritage. 99-107.

Collier, P., D. Forrest, and A. Pearson. 2003. "The Representation of Topographic Information on Maps: The Depiction of Relief" The Cartographic Journal Vol. 40/1: 17-26.

Curtis, C. 1911. "Howell's Relief Maps and the Naturalistic Land Model." Science, New Series, American Association for the Advancement of Science 34/863: 45-47.

de Chadarevian. S and N. Hopwood. 2004. Models: The Third Dimension of Science. Stanford: Stanford University Press.

Demaj, D and K. Field. 2012. "Reasserting Design Relevance in Cartography: Some Examples." The Cartographic Journal 49/1: 77-93.

Ferretti, F. 2014. "Pioneers in the history of cartography: the Geneva map collection of Élisée Reclus and Charles Perron." Journal of Historical Geography, 42, 85-95.

Fonstad, M. A., J.T. Dietrich, B.C. Courville, J.L. Jensen, and P.E. Carbonneau. 2013. "Topographic structure from motion: a new development in photogrammetric measurement." Earth Surface Processes and Landforms 38:421-430.

Granado-Castro, G. and A. Martín-Pastor. 2016. "The 3D Model-Map of Cadiz (1779): A Unique Project of Cartography in Modern Spain." The Cartographic Journal, 53/3: 268-281.

Guidi, G., B. Frischer, M. De Simone, A. Cioci, A. Spinetti, L. Carosso, L.L. Micoli, M. Russo, and T. Grasso. 2005. "Virtualizing ancient Rome: 3D acquisition and modeling of a large plaster-of-Paris model of imperial Rome." In Proceedings of SPIE 5665, Videometrics VIII, ed. J. Beraldin, S.F. El-Hakim, A. Gruen, J.S. Walton. 119-133.

Hahmann, T., C. Eisfelder and M.F. Buchroithner. 2012. “Cartographic representation of Dresden's historical development by projecting a movie onto a solid terrain model". In True-3D in Cartography: Autostereoscopic and Solid Visualisation of Geodata. Ed. Buchroithner, M. Berlin Heidelberg: Springer-Verlag.

Hervy, B., R. Billen, F. Laroche, C. Carré, M. Servières, M. Van Ruymbeke, and J.L. Kerouanton. 2012. “A generalized approach for historical mock-up acquisition and data modelling: Towards historically enriched 3D city models." In Usage, usability, and utility of 3D city models, ed. T. Leduc, Moreau G, R. Billen. 1-10

Hodson, Y. 1995 “Mayson's Model of the Lake District" Sheetlines 38: 26-27

Hofschroer, P. 2004. Wellington's Smallest Victory. Faber and Faber Ltd. 
Imhof, E. 1981. Sculpteurs de montagnes. Les reliefs de montagnes en Suisse. Club Alpin Suisse en collaboration avec le Musée alpin suisse de Berne et le Musée du Jardin des Glaciers de Lucerne, Switzerland. $159 \mathrm{pp}$.

Jenkinson, H. I. 1864. Practical guide to the English Lake District. London: Edward Stanford.

Kelly, S. 1991. Victorian Lakeland Photographers. Shrewsbury: Swan Hill Press.

Kember, J. J. Plunkett, J.A. Sullivan. 2012. Popular Exhibitions, Science and Showmanship, 1840-1910. Pittsburgh: University of Pittsburgh Press

Marshall, J.D. and J.K. Watson. 1981. The Lake Counties from 1830 to the mid-twentieth century. Manchester: Manchester University Press.

Ma, N., F. Laroche, B. Hervy, J.L. Kerouanton, A. Addison, L. De Luca, G. Guidi, and S. Pescarin. 2013. "Virtual conservation and interaction with our cultural heritage: Framework for multi-dimension model based interface." In Proceedings of the IEEE Digital Heritage International Congress. ed. A. Addison, L. De Luca, G. Guidi, S. Pescarin.

Mair, T. 2012. "The landscape relief model - An anachronism or still a useful object for contemplating the landscape" In True-3D in Cartography: Autostereoscopic and Solid Visualisation of Geodata. Ed. Buchroithner, M. Berlin Heidelberg: Springer-Verlag.

Niederöst, J. 2005. Das Relief der Urschweiz von Franz Ludwig Pfyffer (1716-1802): 3DRekonstruktion, Analyse und Interpretation. Zürich: Eidgenössische Technische Hochschule

Payne, E. M. 2012 “Imaging Techniques in Conservation." Journal of Conservation and Museum Studies 10/2: 17-29.

Pearson, A. W. 2015. "Relief Model." In The History of Cartography: Volume Six: Cartography in the Twentieth Century. ed. in M Monmonier, University of Chicago Press, Chicago, pp. 1263-1267.

Pearson, A.W. and M. Schaefer. 2009. "A cartometric analysis of the terrain models of Joachim Eugen Müller (1752-1833), using non-contact 3D digitizing and visualization techniques." Cartographica 44: 111-120.

Priestnall, G., J. Gardiner, J. Durrant. J. Goulding. 2012. “Projection Augmented Relief Models (PARM): Tangible Displays for Geographic Information" In Proceedings of Electronic Visualisation and the Arts (EVA 2012). 180187

Räber, S. 2006. "Handmade Relief Models" In Proceedings of the 5th ICA Mountain Cartography Workshop Association of Surveyors of Slovenia and University of Ljubljana, Ljubljana. ed. D. Petrovic. 222-227.

Rase, W-D. 2012. “Creating Physical 3D Maps Using Rapid prototyping techniques." In True-3D in Cartography: Autostereoscopic and Solid Visualisation of Geodata. Ed. Buchroithner, M. Berlin Heidelberg: Springer-Verlag.

Rothrock, G. A. 1969 “The Musee des Plans-Reliefs” French Historical Studies 6/2: 253-256.

Schwarzbach, F., T. Sarjakoski, J. Oksanen, L. Tiina Sarjakoski, S. Weckman. 2012. "Physical 3D models from LIDAR data as tactile maps for visually impaired persons." In True-3D in Cartography: Autostereoscopic and Solid Visualisation of Geodata. Ed. Buchroithner, M. Berlin Heidelberg: Springer-Verlag.

Smith, T. F. 2007. Jonathan Otley, Man of Lakeland. Carlisle: Bookcase

Smith, D. 1985. Victorian Maps of the British Isles. London: BT Batsford Ltd 
Touret, L. 1989 “Charles-François Exchaquet (1746-1792) et les Plans en Relief du Mont-Blanc.” Annals of Science, 46:1, 1-20

Wachowiak, M.J. and B.V. Karas. 2009. "3D Scanning and Replication for Museum and Cultural Heritage Applications." Journal of the American Institute for Conservation 48/2: 141-158.

Warmoes, I. 2012. Le Musée des Plans-Reliefs. Paris: Editions du Patrimoine Centre des Monuments Nationaux

Wordsworth, W. 1810. Guide to the Lakes. Reprint, London: Frances Lincoln Ltd, 2004 